\title{
O PERFIL DE PROFESSORES DA REDE MUNICIPAL DE EDUCAÇÃO DE BELÉ M
}

A diana deJeusDiniz Farias

\begin{abstract}
Resumo: 0 presente artigo apresenta os resultados da pesquisa " $Q$ uem é e quanto ganha o professor daE ducação Básica da Rede M unicipal deE ducação de Belém?", que objetivou traçar um Perfil dos Professores da Rede Municipal de Educação de Belém de acordo com quatro indicadores: sexo; formação; formação por área de atuação; e remuneração. Utilizou-se a pesquisa bibliográfica e documental. Concluiu-se que, de acordo com os indicadores, a maioria dos professores é do sexo feminino; têm formação em nível superior, com exceção dos que atuam na E ducação I nfantil; no que tange à remuneração, a composição salarial demonstra que independentemente da formação, os professores recebem vencimentos iguais e que as gratificações diferenciam o valor das remunerações.
\end{abstract}

Palavras-chave: Perfil dos professores. Rede Municipal de Educação. Educação Básica.

\section{PROFILE OF TEACHERS WORKING IN THE EDUCATIONAL SYSTEM OF THE MUNICIPALITY OF BELÉM}

Abstract: This article presents the results of the research entitled "Who is the Basic E ducation teacher of the M unicipal System of E ducation in Belém, and how much is he (she) paid?" The objective was to draw a profile of teachers working for the Municipality of Belém (State of Pará, B razil) according to four indicators: sex; teacher education; specific training according to practice area; remuneration. Bibliographic and documentary research was used. A ccording to the indicators, conclusions were reached that most teachers arefemale, holders of higher education degrees with the exception of those working in Early Childhood Education; with regard to remuneration, data evidenced that regardless of their training, teachers receive equal salaries, the differences in the overall remuneration being due to bonuses.

Keywords: Profile of teachers. Municipal Education. Basic Education.

* Graduada em Pedagogia (Licenciatura Plena). M estranda em E ducação (U niversidade Federal do Pará). 


\section{INTRODUÇÃO}

0 destaque para a situação dos professores se dá em função do reconhecimento, quase generalizado, teo ricamente, de que qualidade de ensino está diretamente associada à valorização dos profissionais da educação. Desse modo, as investigações sobre a situação dos professores da Educação Básica se revestem de importància, na medida em que possibilitem ampliar as discussões tanto sobre as avaliações de políticas a eles direcionadas quanto sobre a definição de novas políticas mais consequentes. A ssim sendo, a importância do estudo ora apresentado caminha na direção de subsidiar os estudos e discussões acerca da formação, profissionalização bem como da valorização dos professores da Educação Básica.

No decorrer da história, a escola teve um papel de destaque, pois é considerada a maior responsável pela transmissão de conhecimentos por intermédio de um corpo docente que nem sempre recebeu a devida atenção, principalmente no que tange à garantia de condições adequadas de trabalho e remuneração digna. Essa afirmação ganha apoio quando se analisam os últimos estudos sobre a situação do professor brasileiro. A título de exemplo, podemos citar os Censos do Professor (1997 e 2003) e as pesquisas sobre perfil do professor brasileiro (em 2004 e 2006)i. Tais estudos mostram as grandes desigualdades regionais em relação à formação inicial e continuada, às condições de trabalho e à remuneração dos professores. É importante ressaltar que tais desigualdades não se apresentam apenas de uma região para outra, como também dentro da mesma região, E stado ou Município.

0 presente estudo se constitui peça para avaliar o tripé da valorização docente, ou seja, formação, condições de trabalho e remuneração dos professores. A valorização dos professores não é um tema novo, sempre esteve presente nas discussões políticas, nas propostas, nos planos de governo, em programas oficiais. Mas foi somente a partir do final dos anos de 1980, nas lutas em prol da Constituinte e da Lei de Diretrizes e Bases da Educação Nacional (LDBN), que os professores estiveram no centro das discussões sobre os problemas educacionais. Muitas dessas discussões e conquistas foram resultados de grandes mobilizações sociais e da luta dos educadores. Destacam-se: a Confederação Nacional dos Trabalhadores em Educação (CNTE) $)^{i i i}$, como principal órgão de representação sindical dos professores da E ducação Básica; a A ssociação N acional pela Formação dos Profissionais da Educação (Anfope) ) $^{\text {iv }}$ principal entidadeque discutee promove a formação dos profissionais da educação; dentre outras entidades.

Os professores da Educação Básica pública, no Brasil, são herdeiros de uma histórica constituição da profissão. Inicialmente, os professores eram os

104

Ver a E ducação, v. 12, n. 1, p. 103-122, jan./ jun. 2011 
religiosos (jesuítas) que vieram para o Brasil para catequizar índios e não recebiam salário, mas eram financiados pela Coroa portuguesa. Depois, com a expulsão dos jesuítas, tivemos a substituição de um corpo docente religioso por um corpo docente laico, que recebe salário como retribuição de seu trabalho. Sobre o perfil do professorado, esse último passa a ser, em sua maioria, constituído de "moços pobres e moças ricas". Mais tarde, com a proletarização da profissão, o perfil que se revela é de profissionais oriundos das camadas populares com as mais diversas formações. As mulheres passam a constituir maioria, pois viam, na profissão, a possibilidade de conciliá-la com as tarefas domésticas e auxiliar na despesa familiar. $0 \mathrm{~s}$ professores também foram se organizando enquanto classe e reivindicando seus direitos (MONLEVADE, 2000; NUNES; MONTEIRO; SANTOS, 2008; CNTE, 1997).

O presente trabalho teve por objetivo geral traçar um perfil do professor da Rede Municipal de Educação de Belém. Diante da realidade apresentada, questionou-se: Q uem ée quanto ganha o professor da Rede M unicipal de E ducação de B elém?

\section{METODOLOGIA}

Para traçar 0 perfil dos professores que atuam na E ducação Básica da Rede Municipal de Belém, adotou-se a pesquisa documental, pois, segundo Gil (1991), é a mais adequada para realizar uma análise contextualizada das informações contidas nas fontes documentais a serem analisadas. N esse sentido, adotaram-se quatro indicadores de perfil: I - sexo; II - formação; III - formação conforme área de atuação; e IV - remuneração.

Os indicadores formaçãa e formaçãa conforme área de atuação foram escolhidos devido à disponibilização de Microdados do Censo Escolar (MEC/INEP) que foram tratados pelo grupo de pesquisa coordenado pela Profa $D$ rạ Andréa Barbosa G ouveia, da U niversidade Federal do Paraná. O s dados referentes ao indicador remuneração foram obtidos em tabelas salariais publicadas no Diário Oficial do M unicípio (D O M ), disponibilizadas pela Secretaria M unicipal de A dministração (SE M AD) e tratadas pelo G rupo de Estudos em G estão e Financiamento da Educação (GEFIN). As informações relativas ao indicador sexo foram obtidas por meio de tabelas disponibilizadas pelo $\mathrm{D}$ epartamento de Recursos $\mathrm{H}$ umanos, da Secretaria Municipal de Educação (SEMEC). 


\section{Análise e D iscussão}

\section{Perfil dos professores da Educação Básica da Rede Municipal de Belém}

I Sexo

No que diz respeito ao indicador sexo no grupo de professores pesquisados, elaboramos a tabela a seguir que mostra a distribuição de docentes do sexo masculino e feminino, na E ducação I nfantil, no Ensino Fundamentalv e na E ducação de Jovens e A dultos (EJA).

Tabela 1 - Sexo dos professores segundo área de atuação na Rede Municipal de E ducação de Belém. 2006-2011.

\begin{tabular}{c|c|c|c|c|c|c|c|c}
\hline \multirow{2}{*}{ Anos } & \multicolumn{2}{|c|}{$\begin{array}{c}\text { Educação } \\
\text { Infantil }\end{array}$} & \multicolumn{2}{c|}{$\begin{array}{c}\text { Ensino } \\
\text { Fundamental }\end{array}$} & \multicolumn{2}{c|}{ EJA } & \multicolumn{2}{c}{ Total } \\
\cline { 2 - 9 } & Masc. & Fem. & Masc. & Fem. & M asc. & Fem. & Masc. & Fem. \\
\hline 2006 & 9 & 448 & 587 & 1.592 & 269 & 324 & 865 & 2.364 \\
\hline 2007 & 8 & 401 & 568 & 1.488 & 260 & 307 & 836 & 2.196 \\
\hline 2008 & 8 & 368 & 546 & 1.426 & 245 & 298 & 799 & 2.092 \\
\hline 2009 & 6 & 346 & 522 & 1.383 & 253 & 262 & 781 & 1.991 \\
\hline 2010 & 5 & 292 & 518 & 1.273 & 223 & 246 & 746 & 1.811 \\
\hline 2011 & 4 & 290 & 516 & 1.228 & 219 & 228 & 739 & 1.746 \\
\hline
\end{tabular}

Fonte: BELÉM: SEMEC, 2011 [Oficio à pesquisadora].

De acordo com as informações da tabela, as professoras representam a maioria na Educação Básica, tanto na E ducação I nfantil (creche e pré-escola) quanto no E nsino Fundamental ena EJA. E m 2006, o sexo feminino representava $73,21 \%$ do total de professores contra $26,79 \%$, que representavam o sexo masculino. Em 2011, novamente as mulheres representam a maioria $(70,26 \%)$, enquanto os homens representavam $29,74 \%$ do total.

D estaca-se que a presença masculina, na E ducação Infantil, é a menor em todas as etapas e modalidades analisadas na série histórica. E m 2006, foram apenas $1,97 \%$, enquanto a presença feminina foi de $98,03 \%$; e em 2011 , a presença masculina é de $1,36 \%$ ao passo que a feminina foi de $98,64 \%$, ou seja, a presença feminina, na E ducação I nfantil, constitui quase a totalidade dos sujeitos.

No Ensino Fundamental, a presença masculina aumenta em relação à Educação Infantil. Em 2006, os homens representavam 26,94\% do total de professores que atuam no E nsino Fundamental, enquanto a presença feminina foi de 73,06\%. Em 2011, essa concentração continua, pois os homens representavam $29,59 \%$ do total de professores e as mulheres, $70,41 \%$.

$\mathrm{N}$ a E ducação de Jovens e A dultos, observa-se um equilíbrio de atuação de professores do sexo masculino e feminino, constatado pelo dado que indicava, 
em 2006, os homens representando $45,36 \%$ do total, e as mulheres, 54,64\%. Em 2011, observa-se concentração equilibrada de homens e mulheres atuando na EJA, na ordem de $48,99 \%$ e $51,01 \%$, respectivamente.

Podemos inferir que na Rede Municipal de Educação de Belém 0 professorado é majoritariamente feminino $(70,36 \%)$.

\section{Formação}

No que concerne à formação dos professores, utilizou-se o número de funções docentes em vez de número de docentes, em razão de os microdados do Censo Escolar (INEP/MEC) se referirem somente a funções docentes, de 1996 a 2006; a partir de 2007, os dados se referem ao número de professores. No entanto, entendemos que o número de docentes oferece mais exatidão e é mais realista do que o número de funções docentes. A Tabela 2, a seguir, apresenta o número de funções docentes, por etapa ou modalidade de ensino.

Tabela 2 - Número de funções docentes por etapa ou modalidade da Rede Municipal de Educação de Belém - 1996; 2001; 2006-2009.

\begin{tabular}{|c|c|c|c|c|c|c|c|c|}
\hline \multirow[t]{2}{*}{ Ano } & \multirow{2}{*}{$\begin{array}{c}\text { E ducação } \\
\text { Infantil }\end{array}$} & \multicolumn{2}{|c|}{$\begin{array}{c}\text { E nsino } \\
\text { Fundamental }\end{array}$} & \multirow{2}{*}{$\begin{array}{l}\text { Ensino } \\
\text { Médio }\end{array}$} & \multirow{2}{*}{$\begin{array}{c}\text { Classes de } \\
\text { Alfabetização }\end{array}$} & \multirow{2}{*}{$\begin{array}{l}\text { E ducação } \\
\text { de Jovens } \\
\text { e adultos }\end{array}$} & \multirow{2}{*}{$\begin{array}{c}\text { E ducação } \\
\text { especial }\end{array}$} & \multirow[t]{2}{*}{ Total } \\
\hline & & 1 & 11 & & & & & \\
\hline 1996 & 238 & 898 & 515 & 7 & 60 & 278 & - & 1.996 \\
\hline 2001 & 669 & 1.330 & 618 & 28 & - & 605 & 4 & 3.254 \\
\hline 2006 & 727 & 1.190 & 661 & 35 & - & 696 & 2 & 3.311 \\
\hline 2007 & 398 & 296 & 166 & - & - & 274 & - & 1.134 \\
\hline 2008 & 465 & 768 & 242 & 7 & - & 302 & - & 1.784 \\
\hline 2009 & 527 & 823 & 208 & 19 & - & 275 & - & 1.852 \\
\hline
\end{tabular}

Fonte: INEP. Microdados do Censo Escolar 1996-2009.

De acordo com os dados da Tabela 2, na E ducação I nfantil, houve um aumento de 121,43\% no número de funções docentes, de 1996 a 2009. No Ensino Fundamental (séries iniciais), houve uma queda de $8,35 \%$ no mesmo período. Já nas séries finais, a queda foi de 59,61\%. No Ensino Médio, em 1996, registraran-se sete funções docentes e, em 2009, 19; ou seja, ocorreu um aumento de 171,43\%, que em termos absolutos, todavia, não representou crescimento significativo. $\mathrm{Na}$ EJA, de 1996 a 2009, houve diminuição de três funções docentes (de 278 para 275), o que revela, ao mesmo tempo, regularidade no número de funções docentes e não crescimento. Nas Classes de Alfabetização, só foram registradas, na série histórica, funções docentes no ano de 1996 (60 funções) $)^{\text {vi }}$. N a E ducação E special, só foram consignadas funções docentes em 2001 (quatro) e em 2006 (dois), e nenhuma, em 2009. Na verdade, esse não registro de funções docentes, na Educação Especial, 
é devido ao estudo ter considerado somente as informações referentes às escolas especializadas e escolas de ensino regular com sala de recursos, ou seja, considerouse 0 processo de inclusão, no qual 0 atendimento de alunos com necessidades educativas especiais é feito em turmas regulares ou sala de recursos.

D iante dos dados apresentados, podemos inferir que, no geral, houve um decréscimo de 7,21\% no número de funções docentes da Educação Básica, da Rede Municipal de Belém, pois, em 1996, eram 1.996 funções, caindo, em 2009, para 1.852. Pode-se associar isso ao fato de a Prefeitura de Belém não realizar concurso público para professores há mais de 10 anos, como já mencionado nesse trabalho.

A tabela seguinte apresenta o número de funções docentes por nível de formação na Educação Básica de 1996 a 2009.

Tabela 3 - Número de funções docentes por nível de formação na Educação Básica da Rede Municipal de Belém - 1996; 2001; 2006-2009.

\begin{tabular}{|c|c|c|c|c|c|c|c|}
\hline \multirow{2}{*}{ ANO } & \multicolumn{2}{|c|}{$\begin{array}{c}\text { ENSINO } \\
\text { FUNDAMENTAL }\end{array}$} & \multicolumn{2}{|c|}{ E N SINO MÉDIO } & \multicolumn{2}{|c|}{ EN SIN O SU PERIOR } & \multirow[t]{2}{*}{ TOTAL } \\
\hline & Incompleto & Completo & M agistério & $\begin{array}{c}\text { Sem } \\
\text { M agistério }\end{array}$ & Licenciatura & \begin{tabular}{|c|} 
Sem \\
Licenciatura
\end{tabular} & \\
\hline 1996 & 67 & 142 & 794 & 81 & 828 & 66 & 1.978 \\
\hline 2001 & 19 & 93 & 1.299 & 56 & 1.415 & 371 & 3.253 \\
\hline 2006 & 4 & 12 & 482 & 20 & 1.508 & 103 & 2.129 \\
\hline 2007 & 10 & 10 & 138 & 256 & 720 & 0 & 1.134 \\
\hline 2008 & 8 & 11 & 12 & 412 & 561 & 0 & 1.004 \\
\hline 2009 & 10 & 10 & 17 & 595 & 1.310 & 0 & 1.942 \\
\hline
\end{tabular}

Fonte: INEP. Microdados do Censo Escolar 1996-2009.

De acordo com os dados, os ocupantes das funções docentes com formação de ensino fundamental incompleto caíram 85,07\%, de 1996 a 2009. Aqueles com formação completa no ensino fundamental também diminuíram 92,96\%. Também as que possuíam ensino médio - magistério foram reduzidas $97,86 \%$. Já as que possuíam apenas o ensino médio cresceram $634,57 \%$. Os que possuíam o nível superior (com e sem licenciatura) aumentaram aproximadamente 46,86\%.

A partir da promulgação da LDB, de 1996, em que se passou a fazer maior exigência com relação à escolaridade mínima para a docência na E ducação Básica, percebe-se a queda no número de funções docentes sem a formação mínima exigida e 0 aumento de professores com o nível superior. No tópico a seguir, veremos mais detalhadamente a formação dos professores em cada etapa da E ducação Básica, da Rede Municipal de E ducação.

108

Ver a E ducação, v. 12, n. 1, p. 103-122, jan./ jun. 2011 


\section{Formação conforme a área de atuação}

Sobre esse indicador, apresentamos a formação dos professores por área de atuação, ou seja, por etapa e modalidade de atuação na Educação Básica da Rede M unicipal deB elém. N esse indicador, também foram usados os microdados do Censo Escolar e, para contagem dos professores, utilizaram-se as funç̃oes docentes. A Tabela 4, a seguir, apresenta o número de funções docentes, por nível de formação, na E ducação Infantil.

Tabela 4 - Número de funções docentes, por nível de formação, na Educação Infantil da Rede Municipal de Educação de Belém - 1996; 2001; 2006-2009.

\begin{tabular}{|c|c|c|c|c|c|c|c|}
\hline \multirow{2}{*}{ ANO } & \multicolumn{2}{|c|}{$\begin{array}{c}\text { ENSINO } \\
\text { FUNDAMENTAL }\end{array}$} & \multicolumn{2}{|c|}{ ENSINO MÉDIO } & \multicolumn{2}{|c|}{ EN SIN O SUPERIOR } & \multirow[t]{2}{*}{ TOTAL } \\
\hline & Incompleto & Completo & M agistério & $\begin{array}{c}\text { Sem } \\
\text { M agistério }\end{array}$ & Licenciatura & \begin{tabular}{|c|} 
Sem \\
Licenciatura
\end{tabular} & \\
\hline 1996 & 19 & 36 & 136 & 14 & 33 & - & 238 \\
\hline 2001 & 13 & 51 & 429 & 24 & 87 & 65 & 669 \\
\hline 2006 & 1 & 8 & 320 & 6 & 322 & 70 & 727 \\
\hline 2007 & 3 & 3 & 138 & 155 & 99 & - & 398 \\
\hline 2008 & 8 & 8 & 11 & 150 & 288 & - & 465 \\
\hline 2009 & 9 & 9 & 12 & 301 & 286 & - & 617 \\
\hline
\end{tabular}

Fonte: INEP. Microdados do Censo Escolar 1996-2009.

De acordo com os dados acima, os titulares de funções docentes com formação apenas de ensino fundamental vem caindo, mas ainda se mantêm os que são formados apenas no nível médio. N o entanto, para os que possuem formação em nível superior, esse número vem crescendo significativamente (766\%, em 13 anos). Essa constatação é positiva, haja vista que a LDB, de 1996, admite, para docência na E ducação Infantil, professores com formação em nível médio na modalidade $\mathrm{N}$ ormal (antigo magistério).

No entanto, conforme dados da Tabela 4, o número de funções docentes com formação em nível médio-magistério diminuiu $91,18 \%$, e os professores com formação em nivel médio sem magistério cresceu mais de $2.000 \%$ (passou de 14 funções, em 1996, para 301, em 2009). Esse dado é alarmante, pois deveria ser o contrário. Como vimos, na primeira seção desse artigo, a Lei do FUNDEF (Lei $n^{\circ} 9.424 / 96$ ) destinava parte dos $60 \%$ dos recursos do Fundo para prover a formação dos profissionais sem a titulação exigida, por um período de até cinco anos, mas o M unicípio de Belém não recebeu os recursos do FUNDEF. Além disso, de acordo com essa Lei, os professores só passariam a ser admitidos pela via do concurso público com a titulação mínima exigida.

Segundo o Estatuto do Magistério Público, do Município de Belém (Lei $\mathrm{n}^{\circ} 7.7528 / 91$, que dispõe sobre a estruturação das carreiras e da organização das 
atividades do magistério), para provimento de professor pedagógico (M AG 01) e professor em estudos adicionais (M AG 02) exigir-se-á formação em nível médiomagistério e nível médio-estudos adicionais, respectivamente. D e acordo com os dados, esse critério não está sendo obedecido.

Com relação ao número de funções docentes cujos ocupantes têm formação de nivel superior, o percentual de crescimento foi significativo, $757,58 \%$, pois, ainda que a LDB/1996 admita professores com nível médio, estes se constituem em quadro em extinção, na Rede Municipal de E ducação de Belém. A Tabela 5, a seguir, apresenta o número de funções docentes, por nível de formação, nas séries iniciais do Ensino Fundamental.

Tabela 5 - Número de funções docentes, por nível de formação, nas séries iniciais do Ensino Fundamental da Rede Municipal de Educação de Belém - 1996; 2001; 2006-2009.

\begin{tabular}{|c|c|c|c|c|c|c|c|}
\hline \multirow{2}{*}{ ANO } & \multicolumn{2}{|c|}{$\begin{array}{c}\text { EN SINO } \\
\text { FUNDAMENTAL }\end{array}$} & \multicolumn{2}{|c|}{ ENSINO MÉDIO } & \multicolumn{2}{|c|}{ EN SIN O SUPERIOR } & \multirow[t]{2}{*}{ TOTAL } \\
\hline & Incompleto & Completo & M agistério & Outros & Licenciatura & $\begin{array}{c}\text { Sem } \\
\text { Licenciatura }\end{array}$ & \\
\hline 1996 & 35 & 73 & 513 & 42 & 215 & 20 & 898 \\
\hline 2001 & 5 & 36 & 697 & 16 & 460 & 116 & 1330 \\
\hline 2006 & - & - & 329 & 15 & 734 & 112 & 1190 \\
\hline 2007 & 5 & 5 & - & 73 & 213 & - & 296 \\
\hline 2008 & 3 & 3 & 1 & 225 & 536 & - & 768 \\
\hline 2009 & 1 & 1 & 5 & 269 & 547 & - & 823 \\
\hline
\end{tabular}

Fonte: INEP. Microdados do Censo Escolar 1996-2009.

Os dados da Tabela 5 revelam que o número de funções docentes cujos ocupantes têm formação em E nsino F undamentalvii caiu bastante (de 108, em 1996, para dois, em 2009). Observa-se, também, que também o número os professores com formação em ensino médio - magistério vem diminuindo (de 513, em 1996, para apenas cinco, em 2009). Já o número dos que possuem nível médio sem magistério cresceu $540,48 \%$, e o dos professores com formação de nível superior ${ }^{\text {viii }}$ aumentou consideravelmente (132,77\% de aumento, no período de 1996 a 2009). Podemos inferir desses dados que o nível de formação dos professores aumentou significativamente, passando a ficar em consonância com as legislações vigentes.

Sobre o número de funções docentes, por nível de formação, nas séries finais do ensino fundamental, verifiquem-se os dados da Tabela 6, a seguir. 
Tabela 6 - Funções docentes, por nível de formação, nas séries finais do ensino fundamental, da Rede Municipal de Educação de Belém - 1996; 2001; 20062009.

\begin{tabular}{|c|c|c|c|c|c|c|c|}
\hline \multirow{2}{*}{ ANO } & \multicolumn{2}{|c|}{$\begin{array}{c}\text { ENSINO } \\
\text { FUNDAMENTAL }\end{array}$} & \multicolumn{2}{|c|}{ E N SINO MÉDIO } & \multicolumn{2}{|c|}{ EN SIN O SU PERIOR } & \multirow[t]{2}{*}{ TOTAL } \\
\hline & Incompleto & Completo & M agistério & $\begin{array}{c}\text { Sem } \\
\text { M agistério } \\
\end{array}$ & Licenciatura & \begin{tabular}{|c|} 
Sem \\
Licenciatura \\
\end{tabular} & \\
\hline 1996 & - & 22 & 44 & 8 & 397 & 44 & 515 \\
\hline 2001 & - & - & 22 & 5 & 502 & 89 & 618 \\
\hline 2006 & - & - & 19 & 6 & 635 & 1 & 661 \\
\hline 2007 & - & - & - & - & 166 & - & 166 \\
\hline 2008 & - & - & - & 1 & 241 & - & 242 \\
\hline 2009 & - & - & - & 2 & 206 & - & 208 \\
\hline
\end{tabular}

Fonte: INEP. Microdados do Censo Escolar 1996-2009.

D e acordo com os dados da Tabela 6, não se registraram, em qualquer dos anos da série histórica, funções docentes cujos titulares tivessem formação de Ensino Fundamental incompleto atuando nas séries finais do Ensino Fundamental. Já com formação de E nsino F undamental completo, foram observadas apenas no ano de 1996 (22 funções). Quanto aos professores com formação em nivel médio (magistério), eles aparecem até 2006 e, em 2009, não mais aparecem professores com esse tipo de formação. $\mathrm{N}$ o entanto, ainda aparecem professores com nível médio sem magistério atuando em 2009 (duas funções docentes). Os que possuem o nível superior (licenciatura) caíram cerca de 50\%.

Esse não aparecimento de funções docentes com formação em Ensino Fundamental e a diminuição de funções docentes com formação em nível médio encontram justificativa nas exigências das legislações. Tanto a LDB/1996 quanto o E statuto do Magistério do M unicípio de Belém exigem nível superior em curso de licenciatura, de graduação plena, para provimento dos professores das séries finais do ensino fundamental em diante. A tabela a seguir apresenta a formação dos professores que atuam no ensino médio. 
Tabela 7 - Número de funções docentes, por nível de formação, no Ensino Médioix da Rede Municipal de Educação de Belém - 1996; 2001; 2006-2009.

\begin{tabular}{|c|c|c|c|c|c|c|c|}
\hline \multirow{2}{*}{ ANO } & \multicolumn{2}{|c|}{$\begin{array}{c}\text { ENSINO } \\
\text { FUNDAMENTAL }\end{array}$} & \multicolumn{2}{|c|}{ ENSINO MÉDIO } & \multicolumn{2}{|c|}{ EN SIN O SU PERIOR } & \multirow[t]{2}{*}{ TOTAL } \\
\hline & Incompleto & Completo & M agistério & Outros & Licenciatura & $\begin{array}{c}\text { Sem } \\
\text { Licenciatura }\end{array}$ & \\
\hline 1996 & - & - & 2 & - & 5 & - & 7 \\
\hline 2001 & - & - & - & - & 10 & 18 & 28 \\
\hline 2006 & - & - & 1 & 2 & 32 & - & 35 \\
\hline 2007 & - & - & - & - & - & - & - \\
\hline 2008 & - & - & - & - & 7 & - & 7 \\
\hline 2009 & - & - & - & - & 19 & - & 19 \\
\hline
\end{tabular}

Fonte: INEP. Microdados do Censo Escolar 1996-2009.

Segundo dados da Tabela 7, desde 2008, não existem funções docentes sem nível superior atuando no Ensino M édio. Vale lembrar que a Rede possui apenas uma escola que oferece Ensino Médio profissionalizante (Escola Bosque), justificando o baixo número de funções docentes. Em 2009, registraram-se 19 funções docentes nesse nível de ensino cujos ocupantes possuem formação em nível superior (licenciatura). Esse dado está em consonância com as legislações federal e municipal, quanto à exigência de formação em nível superior, em curso de licenciatura, para docência nessa etapa da E ducação Básica.

Sobre as Classes de Alfabetização, não existem mais funções docentes nessas classes. O último registro da série histórica é de 1996 e, nesse ano, os professores tinham as mais diversas formações, inclusive fundamental incompleto. A Rede M unicipal não oferta mais esse tipo de ensino.

A tabela a seguir apresenta os dados sobre formação dos professores que atuam na EJA.

Tabela 8 - Número de funções docentes, por nível de formação, na Educação de Jovens e Adultos, da Rede Municipal de Educação de Belém - 1996; 2001; 2006-2009.

\begin{tabular}{|c|c|c|c|c|c|c|c|}
\hline \multirow{2}{*}{ ANO } & \multicolumn{2}{|c|}{$\begin{array}{c}\text { ENSINO } \\
\text { FUNDAMENTAL }\end{array}$} & \multicolumn{2}{|c|}{ ENSINO MÉDIO } & \multicolumn{2}{|c|}{ EN SIN O SUPERIOR } & \multirow[t]{2}{*}{ TOTAL } \\
\hline & Incompleto & Completo & M agistério & Outros & Licenciatura & \begin{tabular}{|c|} 
Sem \\
Licenciatura
\end{tabular} & \\
\hline 1996 & - & - & 71 & 9 & 172 & 26 & 278 \\
\hline 2001 & 1 & 6 & 151 & 11 & 356 & 80 & 605 \\
\hline 2006 & 3 & 4 & 69 & 5 & 485 & 30 & 596 \\
\hline 2007 & 2 & 2 & - & 28 & 242 & - & 274 \\
\hline 2008 & - & - & - & 36 & 266 & - & 302 \\
\hline 2009 & - & - & - & 23 & 252 & - & 275 \\
\hline
\end{tabular}

Fonte: INEP. Microdados do Censo Escolar 1996-2009.

112

Ver a E ducação, v. 12, n. 1, p. 103-122, jan./ jun. 2011 
De acordo com os dados, as funções docentes cujos ocupantes atuam na EJA com formação em E nsino Fundamental incompleto e completo existiram até 2007, mas com o número bem reduzido (duas, em cada ponto da escolarização). Os que possuem formação de nível médio (magistério) aparecem até 2006 (69 funções docentes); no entanto, os que têm formação de nível médio, sem magistério, ainda aparecem em 2009 (23 funções docentes). Sobre os que têm formação em curso superior (licenciatura), verificou-se um crescimento de 46,51\%, de 1996 a 2009. O s que têm formação em curso superior, sem licenciatura, apareceram até 2006. Cabe lembrar que, para a docência na EJA ( $3^{\mathrm{a}}$ e $4^{\mathrm{a}}$ etapas), exige-se a formação em nível superior.

De acordo com os Microdados do Censo Escolar (INEP, 2011), registrou-se pouca ou nenhuma função docente na Educação Especial. Em 2001, verificaramse três funções docentes na Educação Especial, todas com ocupantes portadores de formação em nível superior, sem licenciatura/ com magistério. E $m$ 2006, registraram-se duas funções apenas, e estiveram concentradas na formação de nível médio-magistério.

Segundo a LDB/1996 (art. 59, inciso III), os sistemas de ensino assegurarão "professores com especialização adequada em nível médio ou superior, para atendimento especializado, bem como professores do ensino regular capacitados para a integração desses educandos nas classes comuns". E sse dispositivo legal justifica o processo de inclusão comentado anteriormente. De acordo com informações do Departamento de Recursos Humanos, da SEMEC, existe apenas um professor efetivo atuando na E ducação E special que possui a formação exigida.

D epois de delinearmos quem é o professor, sua formação e atuação na Rede, o próximo tópico será dedicado a apresentarmos dados relativos a quanto ganha esse profissional.

\section{Remuneração}

N esta subseção, apresentaremos tabelas salariais que mostram a composição e a evolução salariais do profissional em questão, de acordo com a formação e com a jornada de trabalho.

A Tabela 9, a seguir, apresenta a evolução do vencimento base de acordo com o nível de formação e com a carga horária que trabalha para o que se utilizou a atualização monetária com base no Índice Geral de Preços -Disponibilidade Interna - IGP-DI/FVG ${ }^{x}$, de maio de 2010. 
Tabela 9 - Evolução do Vencimento Base ${ }^{(*)}$ dos Professores do Quadro Permanente do Magistério (QPM) (Início da Carreira). Município de Belém 1996; 2001; 2006-2010.

\begin{tabular}{|c|c|c|c|c|c|c|c|c|c|}
\hline \multirow{2}{*}{ ANO } & \multicolumn{3}{|c|}{ JORNADA $20 \mathrm{HS}$} & \multicolumn{3}{|c|}{ JORNADA $30 \mathrm{HS}$} & \multicolumn{3}{|c|}{ JORNADA $40 \mathrm{HS}$} \\
\hline & EM & LP & E SP. & $E M$ & LP & ESP & EM & $L P$ & ESP. \\
\hline 1996 & 394,21 & 587,60 & 587,60 & - & 797,45 & 797,45 & 788,41 & $1.007,33$ & $1.007,33$ \\
\hline 2001 & 491,35 & 614,12 & 614,12 & - & 833,44 & 833,44 & 982,70 & $1.052,77$ & $1.052,77$ \\
\hline 2006 & 530,07 & 623,45 & 623,45 & - & 846,13 & 846,13 & $1.060,14$ & $1.068,80$ & $1.068,80$ \\
\hline 2007 & 556,59 & 927,41 & 927,41 & - & $1.258,63$ & $1.258,63$ & $1.113,18$ & $1.589,86$ & $1.589,86$ \\
\hline 2008 & 557,60 & 650,53 & 650,53 & - & 882,86 & 882,86 & $1.115,19$ & $1.115,19$ & $1.115,19$ \\
\hline 2009 & 580,97 & 677,80 & 677,80 & - & 919,87 & 919,87 & $1.161,94$ & $1.161,94$ & $1.161,94$ \\
\hline 2010 & 619,28 & 722,50 & 587,60 & - & 980,53 & 980,53 & $1.238,57$ & $1.238,57$ & $1.238,57$ \\
\hline$\%$ CRES & 57,10 & 22,96 & 22,96 & & 22,96 & 22,96 & 57,10 & 22,96 & 22,96 \\
\hline
\end{tabular}

Fonte: UFPA/GEFIN, 2009 [Corrigido pelo IGPD-I a preço de maio/2010].

(*) No município de Belém, a hora atividade é agregada ao vencimento base.

De acordo com os dados da Tabela 9, a evolução salarial dos professores, de 1996 a 2010, foi de $57,1 \%$, para os professores de nivel médio com carga horária de 20 ou 40 horas. Já a evolução salarial dos professores com nível superior e professores com especialização, com jornada de 20,30 e 40 horas, foi de $22,6 \%$. A Tabela 10, a seguir, revela informações atualizadas referentes à remuneração desses professores.

Tabela 10 - Participação percentual do vencimento base e gratificações na remuneração dos professores do Quadro Permanente do Magistério (QPM) Formação nível médio (início da carreira). Município de Belém - 1996; 2001; 2006-2010.

\begin{tabular}{c|c|c|c|c|c|c}
\hline \multirow{2}{*}{ AN O } & \multicolumn{3}{|c|}{ JO RN ADA 20 HS } & \multicolumn{3}{c}{ JO RN ADA 40 HS } \\
\cline { 2 - 7 } & REM. & $\%$ VENC. & $\%$ GRAT. & RE M. & $\%$ VENC. & $\%$ GRAT. \\
\hline 1996 & 709,57 & 55,56 & 44,44 & $1.419,14$ & 55,56 & 44,44 \\
\hline 2001 & 884,43 & 55,56 & 44,44 & $1.768,86$ & 55,56 & 44,44 \\
\hline 2006 & 954,12 & 55,56 & 44,44 & $1.908,25$ & 55,56 & 44,44 \\
\hline 2007 & $1.001,87$ & 55,56 & 44,44 & $2.003,73$ & 55,56 & 44,44 \\
\hline 2008 & $1.003,67$ & 55,56 & 44,44 & $2.007,35$ & 55,56 & 44,44 \\
\hline 2009 & $1.045,74$ & 55,56 & 44,44 & $2.091,49$ & 55,56 & 44,44 \\
\hline 2010 & $1.114,71$ & 55,56 & 44,44 & $2.229,42$ & 55,56 & 44,44 \\
\hline$\%$ CRES & 57,1 & & & 57,1 & & \\
\hline
\end{tabular}

Fonte: UFPA/GEFIN, 2009 [Corrigido pelo IGP-DI a preço de maio/2010].

(*) No município de Belém não há professor com escolaridade de nível médio lotado com $150 \mathrm{~h}$.

De acordo com os dados da tabela acima, o professor de nível médio com jornada de 20 horas, em 1996, recebia $\mathrm{R} \$ 709,57$ de remuneração, em que $55,56 \%$ correspondiam ao vencimento e $44,44 \%$ se compunham de gratificações. Em 2010, recebia $R \$ 1.114,71$ de remuneração, com os mesmos percentuais de

114

Ver a E ducação, v. 12, n. 1, p. 103-122, jan./ jun. 2011 
vencimento e gratificações. Já o professor com jornada de 40 horas recebia, em $2006, \mathrm{R} \$ 1.419,14$ e, em 2010 , recebia $\mathrm{R} \$ 2.229,42$, com os mesmos percentuais de vencimento e gratificações $(55,56 \%$ e $44,44 \%$, respectivamente).

D estaca-se que há quase uma equiparação entre o vencimento e a(s) gratificação(ções), de modo que, se as gratificações fossem retiradas, a remuneração do professor ficaria bastante prejudicada. Gutierres, Gemaque e Luz (2011) elucidam que, quando esse profissional chegar à aposentadoria, quase metade de sua remuneração será suprimida, haja vista que os proventos não incorporam as gratificações.

O utro aspecto que chama atenção é "a aparente regularidade dos percentuais da composição salarial contrariando a dinâmica de mobilizações da categoria por alterações nesta composição salarial ao longo do periodo." (GUTIERRES; GEMAQUE; LUZ, 2011, p. 21).

A Tabela a seguir apresenta a participação percentual do vencimento base e das gratificações na remuneração dos professores com formação de nível superior.

Tabela 11 - Participação percentual do vencimento base e gratificações na remuneração dos professores do Quadro Permanente do Magistério (QPM) Formação Nível Superior (Início da Carreira). Município de Belém - 1996; 2001; 2006-2010.

\begin{tabular}{c|r|r|r|r|r|r|r|r|c}
\hline \multirow{2}{*}{ AN O } & \multicolumn{3}{|c|}{ JORNADA 20 HS } & \multicolumn{3}{|c|}{ JORNADA 30 HS } & \multicolumn{3}{|c}{ JORNADA 40 HS } \\
\cline { 2 - 10 } & REM. & $\begin{array}{c}\% \\
\text { VENC. }\end{array}$ & $\begin{array}{c}\% \\
\text { GRAT. }\end{array}$ & REM. & $\begin{array}{c}\% \\
\text { VENC. }\end{array}$ & $\begin{array}{c}\% \\
\text { GRAT. }\end{array}$ & REM. & $\begin{array}{c}\% \\
\text { VENC. }\end{array}$ & $\begin{array}{c}\% \\
\text { GRAT. }\end{array}$ \\
\hline 1996 & 393,51 & 45,45 & 54,55 & 534,05 & 35,29 & 64,71 & 674,61 & 45,45 & 54,55 \\
\hline 2001 & 639,40 & 45,45 & 54,55 & 867,77 & 35,29 & 64,71 & $1.096,13$ & 45,45 & 54,55 \\
\hline 2006 & $1.086,77$ & 45,45 & 54,55 & $1.474,95$ & 35,29 & 64,71 & $1.893,09$ & 44,73 & 55,27 \\
\hline 2007 & $1.693,56$ & 45,45 & 54,55 & $2.298,41$ & 35,29 & 64,71 & $2.903,27$ & 45,45 & 54,55 \\
\hline 2008 & $1.304,38$ & 45,45 & 54,55 & $1.770,23$ & 35,29 & 64,71 & $2.236,08$ & 45,45 & 54,55 \\
\hline 2009 & $1.432,2$ & 45,45 & 54,55 & $1.943,70$ & 35,29 & 64,71 & $2.455,20$ & 45,45 & 54,55 \\
\hline 2010 & $1.570,8$ & 45,45 & 54,55 & $2.131,80$ & 35,29 & 64,71 & $2.692,80$ & 45,45 & 54,55 \\
\hline$\%$ CRES & 399,17 & 22,96 & 22,96 & 399,18 & 22,96 & 22,96 & 57,10 & 22,96 & 22,96 \\
\hline
\end{tabular}

Fonte: UFPA/GEFIN, 2009.

D e acordo com os dados, o professor com formação de nível superior e com jornada de 20 horas recebia, em 1996, uma remuneração de $\mathrm{R} \$ 393,51$, em que o percentual de gratificação ultrapassava o percentual de vencimento $(45,45 \%$ e $54,55 \%$, respectivamente). Em 2010 , esse professor passa a receber $R \$ 1.570,80$ e permanece com os mesmos percentuais de vencimento e gratificação.

O professor com jornada de 30 horas recebia, em 1996, R \$534,05e, em 2010, recebia $\mathrm{R} \$ 2.131,80$ (aumento salarial de $399,18 \%$ ), com $35,29 \%$ de vencimento e $64,71 \%$ de gratificações; ou seja, o percentual de gratificação aumenta mais ainda. 
O professor com jornada de 40 horas, em 2006, recebia 674,00 e, em 2010, recebia 2.692,80 (aumento salarial de $399,16 \%$ ); os percentuais de vencimento e gratificação passam a compor $45,45 \%$ e $54,55 \%$, respectivamente.

A Tabela 12, a seguir, mostra as remunerações e a participação percentual de vencimento e gratificação com a atualização pelo IGP-DI/FGV.

Tabela 12 - Participação percentual do vencimento base e gratificações na remuneração dos professores do Quadro Permanente do Magistério (QPM) Formação: Nível Superior (Início da Carreira). Município de Belém - 1996; 2001; 2006-2010.

\begin{tabular}{c|c|c|c|c|c|c|c|c|c}
\hline \multirow{2}{*}{ AN O } & \multicolumn{3}{|c|}{ JORNADA $20 \mathrm{HS}$} & \multicolumn{3}{c|}{ JORNADA 30 HS } & \multicolumn{3}{c}{ JORNADA 40 H S } \\
\cline { 2 - 11 } & REM. & $\begin{array}{c}\% \\
\text { VENC. }\end{array}$ & $\begin{array}{c}\% \\
\text { GRAT. }\end{array}$ & RE M. & $\begin{array}{c}\% \\
\text { VENC. }\end{array}$ & $\begin{array}{c}\% \\
\text { GRAT. }\end{array}$ & RE M . & $\begin{array}{c}\% \\
\text { VENC. }\end{array}$ & $\begin{array}{c}\% \\
\text { GRAT. }\end{array}$ \\
\hline 1996 & $1.292,71$ & 45,45 & 54,55 & $1.754,38$ & 35,29 & 64,71 & $2.216,13$ & 45,45 & 54,55 \\
\hline 2001 & $1.351,05$ & 45,45 & 54,55 & $1.823,03$ & 35,29 & 64,71 & $2.316,10$ & 45,45 & 54,55 \\
\hline 2006 & $1.371,59$ & 45,45 & 54,55 & $1.863,14$ & 35,29 & 64,71 & $2.389,21$ & 44,73 & 55,27 \\
\hline 2007 & $2.040,31$ & 45,45 & 54,55 & $2.775,05$ & 35,29 & 64,71 & $3.497,70$ & 45,45 & 54,55 \\
\hline 2008 & $1.431,16$ & 45,45 & 54,55 & $1.938,60$ & 35,29 & 64,71 & $2.453,42$ & 45,45 & 54,55 \\
\hline 2009 & $1.491,15$ & 45,45 & 54,55 & $2.032,54$ & 35,29 & 64,71 & $2.556,26$ & 45,45 & 54,55 \\
\hline 2010 & $1.589,49$ & 45,45 & 54,55 & $2.157,17$ & 35,29 & 64,71 & $2.724,84$ & 45,45 & 54,55 \\
\hline$\%$ CRES & 22,96 & & & 22,96 & & & 22,96 & & \\
\hline
\end{tabular}

Fonte: UFPA/GEFIN, 2009.

De acordo com os dados, o professor com formação de nível superior e com jornada de 20 horas recebia, em 1996, uma remuneração de $\mathrm{R} \$ 1.292,71 \mathrm{em}$ que o percentual de gratificação ultrapassava o percentual de vencimento $(45,45 \%$ e $54,55 \%$, respectivamente). Em 2010 , esse professor passa a receber $R \$ 1.589,49$ e permanece com os mesmos percentuais de vencimento e gratificação.

O professor com jornada de 30 horas recebia, em 1996, R $\$ 1.754,38$ e, em 2010 , recebia $\mathrm{R} \$ 2.157,17$ (aumento salarial de $22,96 \%$ ), com $35,29 \%$ de vencimento e $64,71 \%$ de gratificações; ou seja, o percentual de gratificação aumenta mais ainda.

$O$ docente com jornada de 40 horas percebia, em $2006, R \$ 2.216,13 \mathrm{e}$, em 2010 , recebia $2.724,84$ (aumento salarial de $22,96 \%$ ); os percentuais de vencimento e gratificação passam a compor $45,45 \%$ e $54,55 \%$, respectivamente.

Sobre os professores que possuem pós-graduação (especialização), a tabela a seguir apresenta os percentuais de composição salarial dessas remunerações.

116

Ver a E ducação, v. 12, n. 1, p. 103-122, jan./ jun. 2011 
Tabela 13 - Participação percentual do vencimento base e gratificações na remuneração dos professores do Quadro Permanente do Magistério (QPM) Formação: Especialização (Início da Carreira). Município de Belém - 1996; 2001; 2006-2010.

\begin{tabular}{c|c|c|c|c|c|c|c|c|c}
\hline \multirow{2}{*}{ AN O } & \multicolumn{3}{|c|}{ JO RNADA $20 \mathrm{HS}$} & \multicolumn{3}{c|}{ JORNADA 30 HS } & \multicolumn{3}{c}{ JORNADA 40 HS } \\
\cline { 2 - 11 } & $\begin{array}{c}\% \\
\text { VENC. }\end{array}$ & REM. & $\begin{array}{c}\% \\
\text { GRAT. }\end{array}$ & $\begin{array}{c}\% \\
\text { VENC. }\end{array}$ & REM. & $\begin{array}{c}\% \\
\text { GRAT. }\end{array}$ & $\begin{array}{c}\% \\
\text { VENC. }\end{array}$ & REM. & $\begin{array}{c}\% \\
\text { GRAT. }\end{array}$ \\
\hline 1996 & 45,45 & 420,34 & 54,55 & 42,55 & 570,46 & 57,45 & 42,55 & 720,61 & 57,45 \\
\hline 2001 & 45,45 & 683,00 & 54,55 & 42,55 & 926,93 & 57,45 & 42,55 & $1.170,87$ & 57,45 \\
\hline 2006 & 45,45 & $1.160,88$ & 54,55 & 42,55 & $1.575,51$ & 57,45 & 41,92 & $2.020,12$ & 58,08 \\
\hline 2007 & 45,45 & $1.809,03$ & 54,55 & 42,55 & $2.455,12$ & 57,45 & 42,55 & $3.101,22$ & 57,45 \\
\hline 2008 & 45,45 & $1.393,32$ & 54,55 & 42,55 & $1.890,93$ & 57,45 & 42,55 & $2.388,54$ & 57,45 \\
\hline 2009 & 45,45 & $1.529,85$ & 54,55 & 42,55 & $2.076,23$ & 57,45 & 42,55 & $2.622,60$ & 57,45 \\
\hline 2010 & 45,45 & $1.677,90$ & 54,55 & 42,55 & $2.277,15$ & 57,45 & 42,55 & $2.876,40$ & 57,45 \\
\hline $\begin{array}{c}\% \\
\text { CRFS }\end{array}$ & & 299,18 & & & 299,18 & & & 299,16 & \\
\hline
\end{tabular}

Fonte: UFPA/GEFIN, 2009. Valor nominal.

De acordo com os dados, em 1996, esse professor recebia de remuneração $R \$ 420,34$ e, em 2010, $R \$ 1.677,90$ (variação de 299,18\%). Os percentuais de vencimento e gratificação são $45,45 \%$ e 54,55 , respectivamente.

$O$ professor com jornada de 30 horas, em 1996, recebia $R \$ 570,00$ e, em 2010, R $\$ 2.277,15$ (variação de $299,17 \%$ ). A composição de vencimento e gratificação equivale a $42,55 \%$ e $57,45 \%$, respectivamente.

Em 1996, o professor com jornada de 40 horas percebia $R \$ 720,61$ e, em 2010 , recebia $R \$ 2.876,40$ (variação de $299,16 \%$ ). Os percentuais são $42,55 \%$ de vencimento e de gratificação, $57,45 \%$. Infere-se que em todas as jornadas de trabalho os percentuais de gratificação ultrapassam os de vencimento.

\section{CONCLUSÃO}

0 presente artigo objetivou apresentar os resultados da pesquisa “Q uem são e quanto ganham os professores da E ducação Básica da Rede M unicipal de Belém.

Sobre o indicador "sexo" chegou-se a conclusão que os professores que atuaram e que atuam na Rede são majoritariamente do sexo feminino (70,26\% do total). E $m$ toda a série histórica (2006 a 2011) e nas etapas (E ducação I nfantil, Ensino Fundamental, Ensino M édio) e modalidades (E ducação de Jovens e A dultos) da E ducação Básica que foram analisadas, as professoras representaram a maioria.

$\mathrm{N}$ a E ducação I nfantil, foi encontrada a maior concentração de professoras (98,03\%, em 2011). No Ensino Fundamental, essa concentração diminui, o 
percentual de mulheres caindo para 73,06\% (2011). Na Educação de Jovens e Adultos, observa-se a menor disparidade entre homens e mulheres, pois 0 percentual de professores do sexo feminino é de $51,01 \%$, ou seja, ocorre um equilíbrio nessa modalidade de ensino.

No que tange ao indicador Formação, verifica-se que, em 2009: 1,03\% possuem somente o Ensino Fundamental; 31,51\% possuem o nível médio; e $67,46 \%$, o nível superior. Destacadamente, o conjunto de legislações que exigem uma titulação mínima para a docência na E ducação Básica estimulou a formação de profissionais que não possuíam a formação mínima exigida, assim como o ingresso por concurso público de provas e títulos somente daqueles profissionais com a formação exigida. As políticas de formação e de valorização do professor (como por exemplo: Pró-Letramento; Pró-Licenciatura; Prolnfantil; PARFOR; dentre outras), também, fizeram impulsionar a formação dos professores. Ressaltase que os Programas de Formação Continuada, da Rede Municipal de Educação de Belém, tanto na gestão de Edmilson Rodrigues quanto na de Duciomar Costa, vêm capacitando os professores dessa Rede.

No que tange ao indicador formą̧ão por área de atuacião, os dados revelaram que as funções docentes da Educação Infantil, em 2009, se distribuíam da seguinte forma: 2,92\%, com Ensino Fundamental; 50,73\%, com Ensino Médio; e 46,35\%, com Educação Superior. No Ensino Fundamental (séries iniciais), em 2009, a formação em nível superior passa a ser maioria (66,46\%), contra 33,29\% com apenas o Ensino Médio e 0,24\% com Ensino Fundamental.

0 nível de formação dos professores da Rede M unicipal de E ducação de Belém está em consonância com a LDBN, de 1996, e com o Estatuto do Magistério do Município de Belém (Lei no $7.528 / 91$ ), pois a formação mínima exigida para o professor da E ducação Infantil e das séries iniciais do Ensino Fundamental é o nível médio (magistério). Constatou-se que o percentual de funções docentes cujos ocupantes têm formação de nível superior ultrapassa o percentual dos que completaram o Ensino Médio. Já nas séries finais do ensino fundamental, o ano de 1996 apresentou a maioria dos professores com curso superior $(85,63 \%)$; os com Ensino Médio somaram 10\% e apenas 4,27\%, com Ensino Fundamental. Já em 2009: a quase totalidade possui o ensino superior $(99,04)$, e $0,96 \%$ possuem o nivel médio. No Ensino Médio, em 2009, 100\% das funções docentes estavam preenchidas por professores que possuíam nível superior. Sobre as funções docentes da EJA, em 2009, 91,64\% tinham feito curso superior, enquanto 8,36\% tinham apenas o Ensino M édio.

Sobreo indicador remuneração, essa pesquisa evidenciou que, de acordo com os dados apresentados, paga-se $\mathrm{R} \$ 1.238,57$ de vencimento base para professores

118

Ver a E ducação, v. 12, n. 1, p. 103-122, jan./ jun. 2011 
com jornada de 40 horas semanais; no entanto, não há diferenciação entre os que possuem formação em nível médio, superior e especialização, pois todos possuem o mesmo vencimento base, diferenciando-se a composição remuneratória apenas nas gratificações. Já a remuneração (vencimento base acrescido de vantagens e adicionais) do professor com nível médio é de $\mathrm{R} \$ 2.229,42$. A composição salarial tem $55,56 \%$ de vencimento e $44,44 \%$ de gratificações. A remuneração do professor com nível superior é de $2.724,84$; sua composição salarial registra $45,45 \%$ para vencimento e $54,55 \%$ para gratificações. A remuneração do professor que possui pós-graduação (especialização) é de $R \$ 2.622,60$, em que $42,55 \%$ são de vencimento e $57,45 \%$ são de gratificações.

Diante disso, constata-se que, na composiç̃ão salarial, as gratificações chegam a quase se igualar com o vencimento e, no caso dos professores com nível superior e com especialização, chegam a ultrapassá-lo. Isto representa um ponto negativo, pois significa que, quando se pensa na aposentadoria desses professores, perderão drasticamente, pois os proventos não incorporam as gratificações. Conclui-se que os professores da Rede Municipal de Educação de Belém são, em sua maioria mulheres, formadas em nível superior, que ganham um vencimento-base de $\mathrm{R} \$$ $1.238,57$, valor maior do que o atual Piso Salarial Profissional Nacional (PSPN).

\section{NOTAS}

I Censo dos Profissionais do Magistério da Educação Básica - 2003 e Censo do Professor - 1997, ambos disponiveis no portal do NEP: http:/ portal.inep.gov.br/

"A pesquisa realizada, em 2004, sobre perfil do professor brasileiro está disponível em: Pesquisa Nacional Unesco. O perfil dos professores brasileiros: o que fazem, o que pensam, o que almejam. São Paulo: M oderna, 2004. A pesquisa de 2006 está disponível em: GATTI, Bernadete Angelina; BARRETO, E Iba Siqueira de Sá. Professores do Brasil: impasses e desafios. Brasília: UNESCO, 2009. 294 p.

III A CNTE tem seu marco no ano de 1945, com as primeiras associações de professores primários. Em 1960, já com 11 estados brasileiros com associações, foi fundada a primeira Confederação: a Confederação dos Professores Primários do Brasil - CPPB. Em 1979, a CPPB teve uma mudança substancial em seu estatuto, incorporando os professores secundários dos antigos ginásios, e passou a se chamar Confederação dos Professores do Brasil - CPB. Em 1990, a CPB passou a se chamar Confederação Nacional dos Trabalhadores em Educação-CNTE, em um Congresso extraordinário cujo objetivo foi unificar várias Federações setoriais da educação numa mesma entidade nacional. 
IV A ANFOPE é uma entidade científica, civil, sem fins lucrativos, sem caráter religioso e político-partidário. Foi criada em 26 de julho de 1990, em Assembleia Nacional do $5^{\circ}$. Encontro Nacional da Comissão Nacional de Reformulação dos Cursos de Formação do Educador (Conarcfe); tem como finalidade fazer avançar o conhecimento no campo da formação e da valorização dos profissionais da educação, por meio da mobilização de pessoas, de entidades e de instituições dedicadas a essa finalidade.

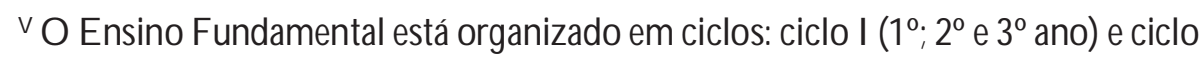
II ( 10 ano e $2^{\circ}$ ano), correspondendo às séries iniciais do E nsino Fundamental. 0 ciclo III ( $1^{\circ}$ ano; $2^{\circ}$ ano) e ciclo IV ( $1^{\circ}$ ano e $2^{\circ}$ ano) correspondem às séries finais do ensino fundamental.

VI N o entanto, de fato, essa oferta terminou, em 2003, quando foram registradas 12 turmas e 10 funções docentes (oito, com formação em nivel superior-licenciatura, e dois, com formação em nível médio - magistério). Essas classes se integraram ao ensino fundamental a partir da implantação do FUN DEF.

VII Somados Ensino Fundamental incompleto e completo

VIII Somados com licenciatura e sem licenciatura.

IX No ano de 2007, não constam informações no sistema de Microdados do Censo Escolar (INEP/MEC) sobre as funções docentes do Ensino Fundamental.

$x$ "O IGP-DI/FGV foi instituído em 1944 com a finalidade de medir o comportamento depreços em geral da economia brasileira. É uma média aritmética, ponderada dos seguintes índices: IPA que é o Índice de Preços no A tacado e mede a variação de preços no mercado atacadista e representa $60 \%$; IPC que é o Índice de Preços ao Consumidor e mede a variação de preços entre as famílias que percebem renda de 1 a 33 salários mínimos nas cidades de São Paulo e Rio de Janeiro e em 30\% o IGP-DI/FGV; INCC que é o Índice Nacional da Construção Civil e mede a variação de preços no setor da construção civil, considerando no caso tanto materiais como também a mão de obra empregada no setor. O INCC pondera em 10\% o IGP-DI/FGV." (GUTIERRES; GEMAQUE; LUZ, 2011, nota 13 , p. 19). 


\section{REFERENNCIAS}

BELÉM (Prefeitura Municipal de). Lei nº 7.502, de 20 de dezembro de 1990. Dispõe sobre o Estatuto do Funcionário Público de Belém. Belém: CEJUP, 1993.

Lei $n^{\circ} 7.507$, de 14 de janeiro de 1991. Dispõe sobre o Plano de Carreira do quadro de pessoal da Prefeitura Municipal de Belém. Belém: CEJUP, 1993.

Lei $n^{\circ} 7.528$, de 5 de agosto de 1991. Estatuto do Magistério. Belém: CEJUP, 1993.

BRASIL. (Constituição, 1988). Constituição da República Federativa do Brasil. Promulgada em 05 de outubro de 1988. Disponível em: < http://www.planalto.gov. br/ccivil_03/Constituicao/Constituicao.htm>. Último acesso em: 4 maio 2011.

. Lei ${ }^{\circ}$ 9.394, de 20 de dezembro de 1996. Estabelece as Diretrizes e Bases da Educação Nacional. Disponivel em: <http://www.planalto.gov.br/ccivil_03/ Leis/L9394.htm>. Último acesso em: 4 maio 2011.

Lei ${ }^{\circ}$ 9.424, de 24 de dezembro de 1996. Dispõe sobre o Fundo de Manutenção e Desenvolvimento do Ensino Fundamental e Valorização do Magistério na forma prevista no art. $60, \$ 7^{\circ}$, do Ato das Disposições Constitucionais Transitórias, e dá outras providências. Publicada no DOU de 26.12.96. Disponível em: http://www.planalto.gov.br/ccivil_03/Leis/L9424compilado.htm. Último acesso em: 4 maio 2011

Lei $n^{\circ}$ 11.494, de 20 de junho de 2007. Regulamenta o Fundo de Manutenção e Desenvolvimento da E ducação Básica e de Valorização dos Profissionais da Educação - FUNDEB, de que trata 0 art. 60 do A to das Disposições Constitucionais Transitórias; altera a Lei no 10.195, de 14 de fevereiro de 2001; revoga dispositivos das Leis nos 9.424, de 24 de dezembro de 1996, 10.880, de 9 de junho de 2004, e 10.845, de 5 de março de 2004; e dá outras providências. Disponivel em: <http://www.planalto.gov.br/ccivil_03/_Ato2007-2010/2007/ Lei/L11494.htm>. Último acesso em: 4 maio 2011.

Lei 11.738 , de 16 de julho de 2008 . Regulamenta a alínea "e" do inciso III do caput do art. 60 do Ato das Disposições Constitucionais Transitórias, para instituir o piso salarial profissional nacional para os profissionais do magistério público da educação básica. Disponível em: <http://www.planalto.gov.br/ ccivil_03/_Ato2007-2010/2008/Lei/L11738.htm>. Último acesso em: 4 maio 2011.

CONFEDERAÇÃO NACIONALDOS TRABALI LADORES EM EDUCAÇ̃OO (CNTE). Cadernos de Educação. Brasília, Ano II, n. 6, ago.1997.

GIL, Antônio Carlos. Métodos e técnicas de pesquisa social. 3. ed. São Paulo: Atlas, 1991. 
GUTIE RRE S, D alva Valente G uimarães; G E MAQUE, Rosana M aria O liveira; LUZ, Sílvia Letícia D'Oliveira da. A carreira dos profissionais do magistério do Sistema Municipal de Educação de Belém: o dito e o feito. In: Congresso Brasileiro de Política e A dministração da E ducação, 25. 2011. São Paulo. AN AIS. Brasília, D F : A ssociação N acional de Política e A dministração da E ducação (AN PAE ), 2011.

INSTITUTO NACIONAL DE ESTUDOS E PESQUISAS EDUCACIONAIS ANÍSIO TEIXEIRA (INEP). Microdados do Censo Escolar 1996-2009. Brasilia:INEP/MEC. [Rede de Pesquisadores em Financiamento da Educação. Dados Educacionais Belém.] Disponivel em: http://www.redefinanciamento. ufpr.br/ pesquisas/remuneracaodeprofessores/ textos/ dados_educacionais/ dados_educacionais.htm. Último acesso: jun. 2011.

MONLEVADE, João Antônio Cabral de. Valorização salarial dos professores. 2000. 307f. Tese (Doutorado em Educação)—Faculdade de Educação, Universidade Estadual de Campinas. Campinas (SP), [s.n.], 2000.

NUNES, Cely do Socorro Costa; MONTEIRO, Albêne Lis; SANTOS, Tânia Regina L obato dos (O rg.). A formação de professores em nível médio normal no Pará: Política, motivações e aspirações profissionais dos alunos. Belém: EDUEPA, 2008.

UNIVERSIDADE FEDERAL DO PARÁ (UFPA). Grupo de Estudos em G estão e Financiamento da E ducação (G E FIN ). Remuneração dos Professores da Educação Básica: configurações, impactos, impasses e perspectivas Projeto de Pesquisa]. Belém: UFPA/GEFIN, 2009. 